\title{
Reputação corporativa nas empresas brasileiras: uma questão relevante para o desempenho empresarial?
}

\author{
Corporate reputation in brazilian companies: is it a relevant matter to business \\ performance?
}

\section{Reputación corporativa en las empresas brasileñas: ¿una cuestión relevante para la evolución de los negocios?}

\section{Vanessa Ingrid da Costa Cardoso}

Mestre em Administração e Controladoria pela UFC

Professora da Faculdade Lourenço Filho e Técnica em Contabilidade da UNILAB

Endereço: Rua Pedro Melo, 558, Bairro Antonio Bezerra

CEP: 60360-220 - Fortaleza/CE - Brasil

E-mail: nessaingrid@gmail.com

Telefone: (85) 8753-9790 / (85) 3235-8779

\section{Márcia Martins Mendes De Luca}

Doutora em Controladoria e Contabilidade pela USP

Professora do Programa de Pós-Graduação em Administração e Controladoria na UFC

Endereço: Av. da Universidade, 2431, Benfica

CEP: 60.020-180 - Fortaleza/CE - Brasil

E-mail: marciadeluca@ufc.br

Telefone: (85) 3366-7802

\section{Gerlando Augusto Sampaio Franco de Lima}

Pós-Doutor em Contabilidade pela University of Illlinois at Urbana-Champaign

Professor Associado do Departamento de Ciências Contábeis e Atuária da FEA/USP

Endereço: Av. Professor Luciano Gualberto, 908, Cidade Universitária

CEP: 05508-900 - São Paulo/SP - Brasil

E-mail: gerlando@usp.br

Fone: (11) 3091-5820

\section{Alessandra Carvalho de Vasconcelos}

Doutora em Engenharia de Produção na Universidade Federal de Santa Catarina

Professora do Programa de Pós-Graduação em Administração e Controladoria da UFC

Endereço: Av. da Universidade, 2431, Benfica

CEP: 60.020-180 - Fortaleza/CE - Brasil

E-mail: alevasconcelos.ufc@gmail.com

Telefone: (85) 3366-7802

Artigo recebido em 18/09/2013. Revisado por pares em 13/10/2013. Reformulado em 19/11/2013. Recomendado para publicação em 23/11/2013 por Sandra Rolim Ensslin (Editora Científica). Publicado em 15/12/2013. 


\title{
Resumo
}

Este trabalho buscou investigar a relação entre a reputação corporativa e o desempenho das empresas, sob a perspectiva teórica da Visão Baseada em Recursos (VBR). Para tanto, foram pesquisadas 84 empresas de capital aberto, classificadas entre as 100 empresas com melhor reputação. O desempenho empresarial foi obtido na base de dados Compustat ${ }^{\circledR}$, enquanto a reputação foi obtida junto ao Reputation Institute. Realizou-se análise de regressão, considerando variável dependente o desempenho e variáveis independentes a reputação corporativa e as variáveis de controle (tamanho e sistema jurídico do país-sede da empresa). Os resultados demonstraram que as empresas com melhor reputação corporativa apresentaram desempenho superior, em conformidade com o que preconiza a VBR.

Palavras-chave: Reputação corporativa. Desempenho empresarial. Visão baseada em recursos.

\begin{abstract}
The present study sought to investigate the relationship between corporate reputation and the performance of companies under the theoretical perspective of the Resource-based view (RBV). To do so, 84 publicly traded companies were investigated, all of which were classified amongst the 100 companies with the best reputation. Business performance was obtained in the Compustat ${ }^{\mathbb{R}}$ database, whereas reputation was obtained in the Reputation Institute. A regression analysis was conducted, taking into account performance as the dependent variable, and corporate reputation along with control variables, such as size and legal system of the company host-country, were considered independent variables. Results show that companies with the best corporate reputation presented greater performance, which is in accordance with what the RBV foretells.
\end{abstract}

Keywords: Corporate reputation. Business performance. Resource-based view.

\section{Resumen}

Este trabajo ha tratado de investigar la relación entre la reputación corporativa y el desempeño de las empresas bajo la perspectiva teórica de la visión basada en recursos (VBR). Para ello, 84 empresas de capital abierto clasificadas entre las 100 empresas con mejor reputación fueron investigadas. La evolución de los negocios se obtuvo a través de la base de datos Compustat $^{\circledR}$, mientras que la reputación se obtuvo del Reputation Institute. Se realizó un análisis de regresión, considerando la evolución de los negocios como siendo la variable dependiente y la reputación corporativa y las variables de control las variables independientes (tamaño y sistema jurisdiccional del país sede de la empresa). Los resultados demostraron que las empresas con mejor reputación corporativa presentan evolución superior, de acuerdo con lo que aboga VBR.

Palabras clave: Reputación Corporativa. Evolución de los negocios. Visión Basada en Recursos. 


\section{Introdução}

É notório o permanente aumento das pressões sob as quais as organizações ficam expostas no mercado, seja por parte de consumidores, concorrentes, investidores e órgãos reguladores, seja pela sociedade em geral. Tal cenário demonstra o interesse dos stakeholders pelas ações e comportamentos das organizações. Nesse sentido, pode-se dizer que o atual contexto mercadológico exige das empresas a conquista de uma boa imagem perante os stakeholders, assim como o seu aprimoramento, pois tal imagem constituirá a reputação corporativa, da qual podem derivar diversos benefícios, destacando-se o melhor desempenho e a vantagem competitiva.

A reputação corporativa consiste no conjunto de atributos organizacionais, desenvolvidos ao longo do tempo, que influencia a forma como os stakeholders percebem a empresa com boa conduta corporativa (ROBERTS; DOWLING, 2002). Portanto, esse conceito tem sido fator relevante no processo de gestão, pois propicia às empresas um diferencial competitivo essencial no cenário de globalização e acirrada concorrência. Por essa perspectiva, alguns estudos destacam que a conquista e preservação de uma boa reputação propicia vantagens perante os concorrentes e consequente melhoria no desempenho (OMBRUN; SHANLEY, 1990; ROBERTS; DOWLING, 2002; THOMAZ; BRITO, 2010; CAIXETA et al., 2011).

Como é permanente a busca por um melhor desempenho empresarial, verifica-se uma incessante discussão científica acerca dos fatores capazes de contribuir para a obtenção dessa melhoria. Observa-se o desenvolvimento de diversas teorias em busca de investigar tal conjuntura, dentre as quais se destaca a Visão Baseada em Recursos (VBR), base do presente estudo, segundo a qual o alcance da vantagem competitiva deriva de recursos específicos da empresa e que não são replicáveis (BARNEY, 1991). Dentre os recursos capazes de favorecer o desempenho empresarial, sobressaem os ativos intangíveis - categoria em que se enquadra a reputação corporativa.

A sinergia dos dois elementos que são os pilares deste estudo, reputação e desempenho, contextualizada pela VBR, pode ser explicada na medida em que a reputação corporativa, resultado de um longo período de apresentação de competências superiores perante suas partes interessadas, é vista como um ativo intangível com potencial de criação de valor, e cuja melhoria continuada poderá se configurar como um fator de influência nas escolhas por investimentos e outras competências essenciais na formação do desempenho empresarial (ROBERTS; DOWLING, 2002).

Nesse contexto, o presente estudo se propõe responder à seguinte questão de pesquisa: Qual a relação entre a reputação corporativa e o desempenho empresarial?

Consequentemente, o objetivo geral deste estudo consiste em investigar a relação entre a reputação corporativa e o desempenho das empresas com melhor reputação, segundo a classificação do Reputation Institute. Adicionalmente, verifica-se a correlação dessas duas variáveis (reputação e desempenho) com o tamanho e o sistema jurídico do país-sede da empresa.

Ressalte-se que a presente pesquisa considera a reputação corporativa um ativo intangível, o que, juntamente com o que preconiza a VBR, que sugere a influência de recursos intangíveis na variação positiva do desempenho empresarial, leva à formulação da seguinte 
hipótese: a boa reputação corporativa correlaciona-se positivamente com o desempenho empresarial.

O estudo foi realizado por meio de uma pesquisa descritiva, com abordagem quantitativa, cuja amostra reuniu 84 empresas de capital aberto classificadas pelo Reputation Institute entre as 100 empresas com melhor reputação. A coleta dos dados relativos ao desempenho empresarial foi efetuada a partir da base de dados Compustat $^{\circledR}$, enquanto o indicador de reputação corporativa foi obtido junto ao Reputation Institute, organização internacional dedicada ao desenvolvimento de estudos e pesquisas acerca da reputação das empresas. A escolha desse indicador se deve ao fato de que o Reputation Institute considera várias dimensões com as quais a reputação está relacionada - desempenho, produtos e serviços, inovação, ambiente de trabalho, governança, cidadania e liderança -, além da sua abrangência mundial, contemplando empresas de todos os continentes. É importante ressaltar ainda que são várias as abordagens possíveis de se estudar a reputação, como reputação sob a perspectiva social e reputação ambiental (ALMEIDA-SANTOS et al., 2012).

Importa verificar se as empresas com melhores índices de reputação conseguem transformar e refletir essa vantagem em aumento no seu desempenho. Destarte, este estudo se insere no contexto das pesquisas que visam entender essa relação, ampliando as contribuições da literatura sobre reputação, que apresenta diversos resultados sobre a sua relação com os vários fatores corporativos, como disclosure, custo de capital, valor da empresa, identidade corporativa, risco de mercado, responsabilidade social corporativa, sustentabilidade e, também, desempenho. Esta pesquisa analisa especificamente a influência da reputação corporativa no desempenho, sob a fundamentação da VBR, e adota uma amostra global, composta pelas empresas listadas no ranking das 100 empresas com melhor indicador de reputação, de acordo com o Global RepTrak ${ }^{\mathrm{TM}}$ Pulse, do Reputation Institute.

\section{Fundamentação Teórica}

\subsection{Reputação Corporativa E Desempenho Empresarial Conforme A Visão Baseada Em Recursos}

O tema reputação corporativa tem se destacado em pesquisas na área de gestão organizacional e despertado interesse relevante, haja vista argumentos que consideram a reputação fator estratégico para a continuidade e o desenvolvimento das organizações.

Frombun e Shanley (1990) foram os precursores da discussão acadêmica acerca da reputação corporativa, cuja obra pioneira preconizava que, em virtude de um mercado mais competitivo, havia uma busca incessante pela sobrevivência corporativa, e que isso poderia ser alcançado pelo desenvolvimento e manutenção de uma boa reputação corporativa (MACHADO FILHO, 2006; FREITAS, 2007).

Há diversas abordagens de aplicação da reputação corporativa nas pesquisas científicas, haja vista sua multidisciplinaridade, ocupando espaço em áreas como estratégia, administração, marketing, contabilidade e gestão. Por conseguinte, não há conceito conclusivo e universalmente aceito sobre a temática.

Segundo Gotsi e Wilson (2001), a reputação corporativa resulta da avaliação geral de uma organização ao longo do tempo por parte dos seus stakeholders. Reforçando tal conceito, Roberts e Dowling (2002) a consideram o conjunto de atributos organizacionais conquistados 
ao longo do tempo, e que refletem o modo pelo qual os stakeholders percebem a empresa como uma boa cidadã corporativa. Essa percepção pode ser estudada de forma geral, ou específica, como, por exemplo, segmentando-a em reputação corporativa financeira, reputação corporativa ambiental e reputação corporativa social.

Nesse sentido, para os propósitos do presente estudo, admite-se que a reputação corporativa refere-se, dentre outros aspectos, à capacidade de uma empresa para atender às expectativas de múltiplos stakeholders, por meio de critérios de julgamento socialmente construídos e legitimados (FOMBRUN; SHANLEY, 1990).

Segundo Barnett, Jermier e Lafferty (2006), o estudo do conceito da reputação pode ser dividido em três tipos de abordagem: ativo, avaliação e percepção. O primeiro caracteriza a reputação como um ativo intangível das organizações; o segundo aduz que a reputação consiste em um produto da avaliação moral dos stakeholders; e o terceiro assimila a reputação a partir da percepção dos stakeholders, mais especificamente dos clientes das organizações.

Vale ressaltar que o presente estudo aborda a reputação como um ativo intangível, representando um recurso capaz de propiciar a conquista da boa reputação, condicionando ainda o melhor desempenho e vantagem competitiva das organizações no mercado de negócios. Segundo Machado e Famá (2011, p. 94), o ativo intangível representa um "ativo de natureza permanente, sem existência física que, em conjunto com os ativos tangíveis, seja capaz de produzir benefícios futuros".

Machado Filho (2006) salienta que a boa reputação das empresas sinaliza aos consumidores e clientes que os produtos e serviços ofertados são de boa qualidade, possibilitando que as empresas exerçam preço premium, com reflexo direto nos seus resultados. Além disso, Machado Filho (2006) ressalta a incidência da boa reputação no contexto interno das empresas, haja vista que a autoestima dos funcionários é afetada positivamente, traduzindo-se em aumento de produtividade. Corroborando essa ideia, Horiuchi (2010) afirma que empresas com boa reputação podem usufruir melhores condições de negócios perante seus stakeholders.

Nesse contexto, emerge a teoria denominada Visão Baseada em Recursos (VBR), ou Resource Based View (RBV), que indica os fatores idiossincráticos, valiosos, raros, de difícil imitação e particulares de cada empresa como preponderantes na explicação da variação do seu desempenho (CARVALHO; KAYO; MARTÍN, 2010).

Conforme leciona Oening (2010, p. 49), a VBR "sustenta que as empresas com estruturas organizacionais e sistemas de coordenação de atividades superiores são lucrativas porque se apropriam de rendimentos extraordinários oriundos da escassez no mercado de recursos específicos da firma."

Segundo Wernerfelt (1984, p. 172), os recursos representam "qualquer coisa que possa ser pensada como uma força ou fraqueza de uma dada firma". Complementarmente, Barney (1991) ressalta que tais recursos são os ativos, as capacidades, os processos organizacionais, os atributos da firma, a informação e o conhecimento, que estão sob o controle das empresas e que as habilitam a implementar estratégias visando à eficiência e à efetividade.

Desenvolvendo as perspectivas da VBR, Castro (2009) aduz que a busca por recursos dificilmente replicáveis pelas empresas concorrentes constitui o foco das estratégias empresariais que visam alcançar melhor desempenho do que suas concorrentes, ou seja, vantagens competitivas.

Dessa forma, a implementação de ações desenvolvedoras de competências ou da capacidade de conquista de posição de destaque é capaz de promover melhor desempenho, 
haja vista que aprimora a reputação corporativa. Nessa perspectiva, Carvalho, Kayo e Martín (2010) consideram que a variação observada no desempenho das firmas provém da natureza específica de seus recursos e de competências acumuladas.

Portanto, a reputação emerge como um recurso potencial para a obtenção da vantagem competitiva, pois esta gera valor para seus stakeholders, é rara e não pode ser copiada ou comprada (BRITO, 2005; CASTRO, 2009).

A conquista do melhor desempenho ocorre quando a estratégia da empresa tem um gerenciamento atencioso e competente desde o momento inicial da formação de sua reputação. Além disso, percebe-se que ao longo do tempo o mercado envia feedback para a reputação corporativa, significando que esta é continuamente afetada e sofre influência de todas as ações e interações da empresa. Mahon (2002) destaca que as interações entre os stakeholders da empresa são significativas para a reputação corporativa.

Roberts e Dowling (2002) ressaltam que, pelo fato de a reputação corporativa ser determinada por esforços anteriores, ou seja, ações passadas, em muitos casos as partes interessadas da empresa podem identificar esses esforços por meio da postura desta no mercado, levando os stakeholders a formar impressões que compõem sua reputação. Logo, as impressões ou os sinais que as empresas emitem para o mercado dependem não somente de suas ações anteriores, mas também de seu desempenho financeiro, e isso constitui a reputação corporativa (Figura 1).

Figura 1 - Modelo da dinâmica de reputação e desempenho financeiro

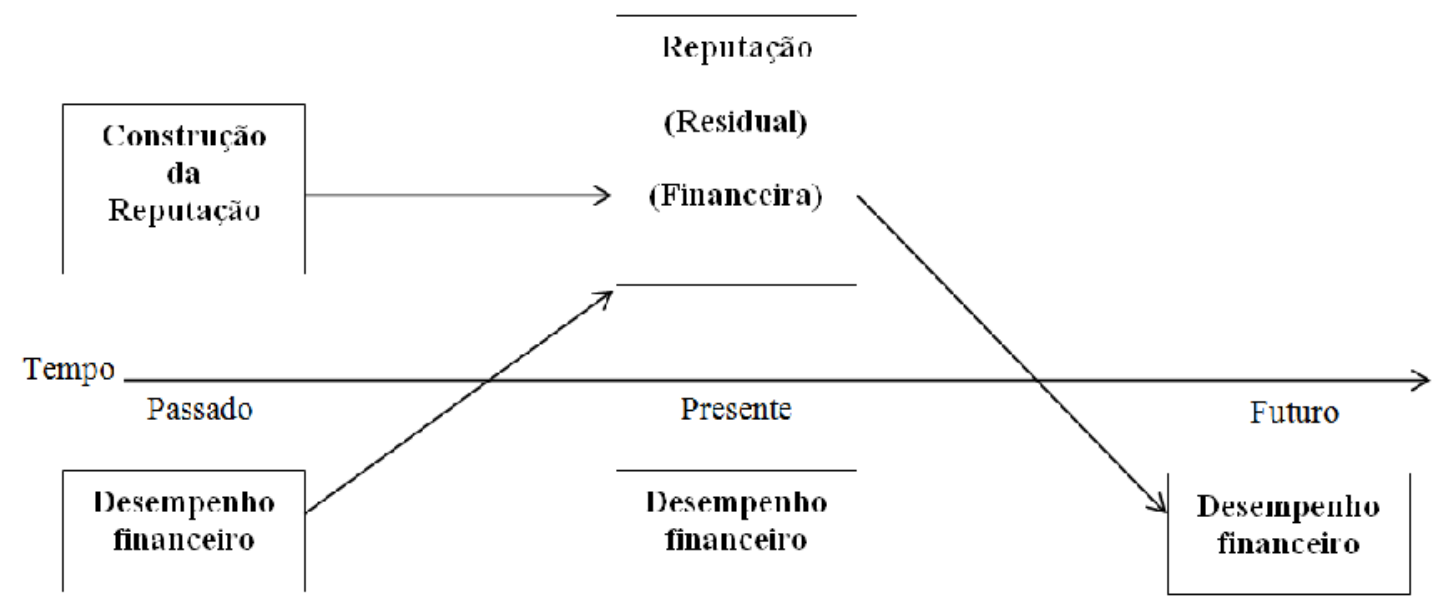

Fonte: Traduzida de Roberts e Dowling (2002, p. 1078).

O modelo da dinâmica da reputação e do desempenho financeiro, mostrado na Figura 1, ilustra que, assim como as manifestações anteriores da postura da empresa no mercado influenciam a reputação corporativa, o seu desempenho financeiro também pode influenciar a reputação corporativa, que, por sua vez, atua na obtenção do desempenho financeiro futuro.

Congregando as opiniões dos autores que abordam essa temática (FOMBRUN; SHANLEY, 1990; LANDON; SMITH, 1997; ROBERTS; DOWLING, 2002; BRITO, 2005; CAIXETA, 2008; HORIUCHI, 2010; THOMAZ; BRITO, 2010; CAIXETA et al., 2011), verifica-se uma variedade de benefícios que a boa reputação é capaz de proporcionar à empresa, destacando-se dentre eles o melhor desempenho. Roberts e Dowling (2002) entendem que há uma relação transversal entre reputação e desempenho financeiro, e que a 
reputação influencia a conquista do desempenho. Os dois referidos autores ressaltam ainda que a reputação é valorizada por si só, ou seja, a conquista da boa reputação corporativa é fator positivo para a sua continuidade e melhoria, e os clientes valorizam as associações e as operações com alta reputação, o que propicia melhores resultados para a empresa. Na mesma linha de raciocínio, Rossoni e Machado-da-Silva (2013) constataram em seu estudo que a reputação da empresa afeta significativamente o seu desempenho, nesse caso avaliado pelo valor de mercado.

Nesse contexto de boa reputação associada a um desempenho superior, são identificados alguns benefícios: os consumidores se dispõem a pagar mais; os empregados preferem trabalhar para empresas com alta reputação, sendo os mais qualificados atraídos pela maior reputação, influenciando a qualidade dos produtos e serviços; os investidores percebem que empresas com mais reputação apresentam riscos mais baixos e mais capacidade de sustentar o desempenho superior; em momentos de crise a boa reputação pode ser favorável e dar suporte à empresa.

Assim, considera-se a VBR uma base para discussão da influência da reputação corporativa no alcance do melhor desempenho empresarial, na medida em que essa abordagem argumenta que a reputação corporativa, considerada um ativo intangível, pode propiciar a conquista de vantagem competitiva, que pode ser representada pelo desempenho superior. A vantagem competitiva se destaca ainda como forma de sustentar e melhorar tal desempenho a partir da potencialização de recursos não replicáveis por outras empresas, como a reputação (BRITO, 2005; CASTRO, 2009).

\subsection{Estudos Empíricos Anteriores}

No que tange à temática reputação corporativa relacionada ao desempenho empresarial, foram identificados vários estudos nacionais e estrangeiros. Apesar de as pesquisas estrangeiras serem mais frequentes, há de se considerar que, de forma abrangente, realizam maior quantidade de pesquisas teóricas e direcionadas a propostas de aplicação de metodologia de mensuração da reputação corporativa. Enquanto isso, as pesquisas nacionais são mais empíricas e voltadas para análise de relações da reputação com outros elementos empresariais.

No âmbito nacional, destacam-se os estudos de Brito (2005), Caixeta (2008), Horiuchi (2010), Thomaz e Brito (2010) e Caixeta et al. (2011).

Brito (2005) investigou a relação entre a reputação corporativa e seus componentes e o desempenho econômico de agências de um dos maiores bancos privados nacionais. Foram entrevistados 595 clientes e 104 colaboradores de 15 agências, constatando-se uma baixa correlação entre a percepção da imagem e da reputação das agências pelos clientes e os respectivos desempenhos econômicos. Contudo, a percepção da identidade e da imagem das agências pelos colaboradores explicou aproximadamente $70 \%$ da variação do desempenho econômico das agências pesquisadas.

Ao pesquisar, também, sobre a correlação entre reputação e desempenho de cinco grupos empresariais brasileiros, Caixeta (2008) verificou se a reputação, medida pelas dimensões governança, desempenho e produtos e serviços, está diretamente relacionada aos seus resultados econômico-financeiros, representados por um conjunto de indicadores previamente selecionados. De acordo com os resultados, não se verificou uma associação direta, para o público em geral, entre o desempenho econômico-financeiro e a reputação das 
empresas, cuja mensuração se deu a partir da metodologia do Reputation Institute. O estudo constatou ainda ser essencial o empenho das empresas no gerenciamento da reputação corporativa em busca de uma estruturação e uma atuação mais eficientes da gestão estratégica e no gerenciamento das ações com todos os stakeholders, tornando isso um diferencial competitivo no mercado e, consequentemente, destacando-se em desempenho.

Tais resultados foram constatados em estudo posterior de Caixeta et al. (2011), também abordando possíveis relações entre reputação e desempenho econômico-financeiro, em seis grupos empresariais brasileiros: Embraer, Pão de Açúcar, Petrobras, Vale e Votorantim. Os autores concluíram que aquelas percepções sobre a reputação (governança, desempenho e produtos e serviços) não necessariamente estão condicionadas a resultados econômicos vultosos. Dito de outra forma, a pesquisa indica que parece não haver uma relação direta, para o público em geral, entre o desempenho econômico-financeiro e a reputação das empresas, especificamente nas três dimensões que poderiam demonstrar essa inter-relação imediata, ou seja, governança, desempenho e produtos e serviços.

Integrando também o rol de pesquisas sobre a relação entre reputação e desempenho corporativo, Horiuchi (2010) pesquisou empiricamente a relação entre reputação corporativa e valor de mercado das companhias com ações negociadas nas bolsas brasileiras. Foram objeto de estudo do autor "As Empresas Mais Admiradas do Brasil", no período entre 2002 e 2005. Os resultados demonstraram haver relação entre os dois aspectos, haja vista que as empresas com melhor reputação corporativa, segundo o ranking de "As Empresas Mais Admiradas do Brasil”, obtiveram maior avaliação pelo mercado de ações.

Thomaz e Brito (2010) realizaram pesquisa visando mensurar a reputação corporativa e seus antecedentes e analisar a sua relação com o desempenho organizacional, por meio de consulta a colaboradores e clientes de doze empresas brasileiras. Os resultados indicam que há fortes efeitos da comunicação sobre a identificação organizacional e sobre a reputação. A mensuração da reputação corporativa proposta pelo estudo dos dois citados autores consiste em uma escala constituída por 233 atributos, extraídos de 35 artigos, distribuídos em 10 categorias, a saber: qualidade dos produtos/serviços, qualidade do gerenciamento, inovação, responsabilidade social/ambiental, força financeira, qualidade do marketing, liderança de mercado, qualidade da estratégia, produtos e serviços valorizam o dinheiro, habilidade para atrair, desenvolver e reter talentos. Os autores constataram forte impacto da identificação sobre a reputação, indicando que a comunicação e a identificação organizacional consistem em fatores cruciais para a formação da reputação e que esta influencia, em proporção moderada, o desempenho organizacional.

No âmbito internacional, destacam-se estudos relacionando reputação e desempenho de Fombrun e Shanley (1990), Roberts e Dowling (2002) e Schultz, Nielsen e Boege (2002).

Fombrun e Shanley (1990) realizaram estudo empírico com 292 empresas britânicas. A análise considerou variável dependente a reputação corporativa, representada pelo ranking "As Empresas Mais Admiradas da América", da revista Fortune. Os autores perceberam que a rentabilidade, o crescimento, o tamanho, o risco e o desempenho financeiro das empresas possuem alta correlação com a reputação corporativa.

Roberts e Dowling (2002) avaliaram o impacto da reputação corporativa no desempenho organizacional, encontrando uma correlação positiva entre a reputação e o crescimento e a sustentabilidade do desempenho organizacional, ao verificar que empresas com boa reputação, segundo o ranking "As Empresas Mais Admiradas da América”, da

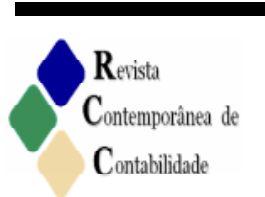


revista Fortune, durante o período de 1984 a 1998, são mais hábeis para conquistar o aumento da lucratividade e a sua sustentabilidade em longo prazo.

Schultz, Nielsen e Boege (2002) estudaram as 25 empresas mais visíveis na Dinamarca, em busca de analisar algumas de suas características e classificá-las quanto ao desempenho, como "melhor" e "pior". Os autores perceberam que as empresas com "melhor" desempenho se encontram no grupo esperado de grandes empresas dinamarquesas com longas histórias. Enquanto isso, percebeu-se a reputação como fator determinante no ambiente de negócios dinamarquês, em se tratando de desempenho.

Do exposto, vale ressaltar que a presente pesquisa pretende verificar a relação entre a reputação corporativa e o desempenho das empresas classificadas pelo Reputation Institute. Diferencia-se, portanto, dos estudos referenciados, levando-se em conta as características da amostra, além das variáveis utilizadas. Os procedimentos metodológicos utilizados para o alcance do objetivo, incluindo a descrição dessas variáveis, são apresentados a seguir.

\section{Metodologia}

$\mathrm{Na}$ tentativa de encontrar uma solução para o problema levantado, realizou-se uma pesquisa descritiva, tendo em vista descrever a relação entre os fatores reputação corporativa e desempenho das empresas participantes do ranking das 100 companhias com melhor reputação corporativa, classificadas pelo Reputation Institute.

A coleta de dados secundários foi realizada por meio da base de dados Compustat $^{\mathbb{R}} \mathrm{e}$ da obtenção do Global RepTrak ${ }^{\mathrm{TM}}$ Pulse, do Reputation Institute, que lista as 100 empresas com melhores indicadores de reputação corporativa.

O universo da pesquisa compreende 100 empresas de capital aberto participantes do ranking do Global RepTrak ${ }^{\mathrm{TM}}$ Pulse, que classifica as empresas com os maiores escores de reputação, realizado pelo Reputation Institute a partir de empresas sediadas nos países de atuação do referido instituto. As 84 empresas que disponibilizaram os dados necessários para a realização do presente estudo constituindo-se, portanto, a amostra da pesquisa, foram distribuídas por setor de atuação, segundo o North American Industry Classification System (Naics), conforme visualizado na Tabela 1.

Tabela 1 - Distribuição quantitativa e proporcional das empresas da amostra por setor de atuação, segundo o Naics

\begin{tabular}{l|c|c}
\hline \multicolumn{1}{c|}{ Setor de atuação } & Quantidade & Proporção (\%) \\
\hline Serviços de alojamento e alimentação & 3 & 3,6 \\
\hline Finanças e seguros & 1 & 1,2 \\
\hline Indústrias da informação e cultural & 5 & 5,9 \\
\hline Fabril & 58 & 69,0 \\
\hline Mineração, pedreiras, petróleo e gás e extração & 1 & 1,2 \\
\hline Administração pública & 3 & 3,6 \\
\hline Serviços profissionais, científicos e técnicos & 1 & 1,2 \\
\hline Imóveis, aluguel e leasing & 1 & 1,2 \\
\hline Comércio a retalho & 3 & 3,6 \\
\hline Transporte e armazenamento & 7 & 8,3 \\
\hline Comércio por atacado & 1 & 1,2 \\
\hline \multicolumn{1}{c|}{ Total } & $\mathbf{8 4}$ & $\mathbf{1 0 0 , 0}$ \\
\hline
\end{tabular}

Fonte: Elaborada pelos autores, a partir do Naics (2012). 
Observa-se, portanto, a predominância do setor fabril, que reúne $69 \%$ das empresas da amostra, sugerindo que mais da metade das 100 empresas classificadas com os melhores escores de reputação corporativa faz parte desse segmento.

Vale salientar que o presente estudo tem natureza quantitativa, na medida em que faz comparações estatísticas entre variáveis e quantifica dados na forma de coleta de informações, empregando recursos e técnicas estatísticos (OLIVEIRA, 2001). Dessa forma, foi aplicada a análise de regressão por Mínimos Quadrados Ordinários, técnica estatística que, de acordo com Fávero et al. (2009, p. 346), "tem como objetivo estudar a relação entre duas ou mais variáveis explicativas, que se apresentam na forma linear". Constitui característica principal da regressão "a existência de dependência estatística de uma variável denominada dependente, ou variável prevista ou explicada, em relação a uma ou mais variáveis independentes, explanatórias ou preditoras" (CUNHA; COELHO, 2007, p. 132).

A investigação da relação entre a reputação corporativa e o desempenho empresarial, para os propósitos desta pesquisa, adota o modelo representado na Equação 1, baseado no modelo básico de regressão múltipla, apresentado por Cunha e Coelho (2007).

$$
\operatorname{LogQTobin}_{i}=\mathrm{REP}_{i}+\operatorname{Tamanho}_{i}+\mathrm{D} 1_{i}+\mathrm{D} 2_{i}+\mathrm{D} 3_{i}(\text { Equação 1) }
$$
Em que:
LogQTobin é o logaritmo natural do $Q$ de Tobin, variável dependente que mede o valor de mercado do ativo para cada empresa $i$;
$\mathrm{REP}_{i}$ é a variável independente $i$, que representa a reputação corporativa para a empresa $i$;
Tamanho $_{i}$ é a variável independente que mede o tamanho da empresa, dado pelo logaritmo do Ativo Total para cada empresa $i$;
$\mathrm{D} 1_{i}$ é a variável independente dummy para Common Law (1) e Outras (0);
$\mathrm{D} 2{ }_{i}$ é a variável independente dummy para Mixed Law (1) e Outras (0);
D3 $i$ é a variável independente dummy para Civil Law (1) e Outras (0).

Conforme a Equação 1 o LogQTobin é a variável dependente e as variáveis independentes são REP, Tamanho, D1, D2 e D3, sendo Tamanho, D1 ${ }_{i}, \mathrm{D} 2_{i}$ e D3 ${ }_{i}$ utilizadas como variáveis de controle. Vale salientar que se trata de uma análise cross section, abrangendo os dados das empresas referentes ao exercício de 2011. Os dados foram tratados no software Stata.

Para melhor compreensão do estudo, faz-se necessária a descrição individualizada das variáveis do modelo. Dessa forma, inicialmente apresenta-se a variável dependente que representa o desempenho empresarial: o $Q$ de Tobin. Essa variável representa "uma medida de avaliação financeira do valor de uma empresa por um julgamento de mercado de longo prazo que incorpora o modelo de risco e retorno nos fluxos de caixa futuros sem precisar usar medidas de risco sistemático" (SILVA, 2009, p. 101). Além disso, o $Q$ de Tobin pauta-se na combinação de dados de mercado com dados contábeis, propiciando a mensuração mais precisa do desempenho empresarial. Esse indicador representa, portanto, a riqueza das empresas, haja vista o seu desempenho no mercado de ações (FAMÁ; BARROS, 2000), e foi obtido mediante divisão da soma do valor de mercado das ações com o valor contábil das dívidas pelo valor contábil do Ativo Total (MURCIA, 2009; DRAGOMIR, 2010). Sua utilização se justifica pela intensidade de sua adoção nas pesquisas acadêmicas (SILVEIRA

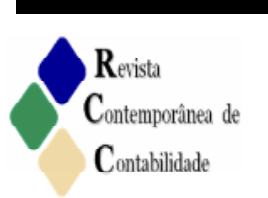


et al., 2004; SILVEIRA; BARROS, 2008; MURCIA, 2009; MURCIA; SANTOS, 2009; PRADO et al., 2009; CARVALHO; KAYO; MARTÍN, 2010; DRAGOMIR, 2010).

No tocante à reputação corporativa, variável independente da pesquisa, destaque-se que já foram realizados alguns estudos com o objetivo de criar uma metodologia para sua mensuração (FOMBRUN; GARDBERG; SEVER, 2000; SCHULTZ; MOURITSEN; GABRIELSEN, 2001; ROBERTS; DOWLING, 2002; MICHELON, 2007). Apesar de ainda não haver um consenso no meio acadêmico que proporcione um índice ou um conjunto de indicadores universal de reputação corporativa, este estudo utiliza o Global RepTrak ${ }^{\mathrm{TM}}$ Pulse, do Reputation Institute, assim como as pesquisas de Almeida (2005), Caixeta (2008), Girard (2009) e Caixeta et al. (2011).

Desenvolvido pelo Reputation Institute, esse indicador é a base para a publicação anual do ranking das empresas com melhor reputação entre os 52 países onde atua o instituto. A pontuação desse ranking admite as particularidades das empresas conforme o país, a região e o setor de atuação. O escore de cada empresa é obtido por meio do framework denominado $\operatorname{RepTrak}^{\mathrm{TM}}$, constituído por sete dimensões da reputação: desempenho, produtos e serviços, inovação, ambiente de trabalho, governança, cidadania e liderança. Essas dimensões possuem 23 diferentes atributos (REPUTATION INSTITUTE, 2013).

Para a realização do Global RepTrak ${ }^{\mathrm{TM}}$ Pulse, o Reputation Institute avalia as empresas com maiores volumes de receita bruta em cada país pesquisado e apenas no país de origem da organização. São distribuídos com o público em geral cerca de 60 mil questionários online, compondo uma média de 100 respondentes por país, que devem avaliar, no máximo, cinco empresas com que tenham familiaridade (GIRARD, 2009).

Destaque-se que no presente estudo a reputação corporativa é considerada fator capaz de influenciar o aumento do desempenho empresarial.

Levando-se em conta que o presente estudo tem como foco a relação entre a reputação corporativa e o desempenho, admite-se que o tamanho da empresa e o sistema jurídico dos países-sede das empresas são variáveis de controle para o tratamento estatístico dos dados. Essas variáveis representam fatores que "o investigador neutraliza ou anula propositalmente em uma pesquisa, com a finalidade de impedir que interfira na análise da relação entre as variáveis independente e dependente" (LAKATOS; MARCONI, 1985, p. 145).

A operacionalização dessas variáveis é expressa da seguinte forma:

a) Tamanho da empresa (TAM): representada pelo logaritmo do Ativo Total da empresa;

b) Sistema jurídico do país-sede da empresa: três variáveis dummies, sendo que D1 é a variável dummy para Common Law (1) e Outras (0); D2 é a variável dummy para Mixed Law (1) e Outras (0); e D3 é a variável dummy para Civil Law (1) e Outras (0).

Ressalte-se que a adoção dessas duas variáveis de controle se deu com base em estudos anteriores, como os de Roberts e Dowling (2002) e Crisóstomo, Freire e Vasconcellos (2010), que também procuraram verificar a influência no desempenho das organizações. Assim, espera-se uma correlação positiva entre o tamanho da empresa e o seu desempenho.

Com relação à variável "sistema jurídico dos países-sede das empresas", destaque-se que o conjunto de normas jurídicas, denominado sistema jurídico, classifica-se de várias formas, havendo, porém, a predominância de três grupos em pesquisas sobre a temática: Common Law, Civil Law e Mixed Law (LA PORTA et al., 1996; BUSHMAN; PIOTROSKI, 2006). O common law, com origem na Inglaterra, consiste no direito baseado na 
jurisprudência, ou seja, na resolução das questões judiciais com base nas particularidades dos casos e nas interpretações das normas do Direito proferidas pelo Poder Judiciário. Enquanto isso o civil law possui características da dominação romana, sendo o texto da Lei a principal fonte do Direito adotada. O mixed law ocorre quando o país adota mais de um sistema jurídico (LA PORTA et al., 1996).

Segundo Carmo, Ribeiro e Carvalho (2011), os países com sistema common law seguem uma orientação de visão justa, transparente e de evidenciação total, sendo considerados mercados da principal fonte de financiamento das empresas, além de destinar as informações contábeis principalmente a atender às necessidades dos acionistas externos, ao passo que países de civil law são caracterizados por uma orientação legalista, de modo que a evidenciação representa apenas o cumprimento de normas. Além disso, há uma diferença marcante no tocante à proteção ao investidor: em países de common law há uma proteção maior do que em países de civil law, e por isso o primeiro sistema caracteriza mercados mais fortes (LA PORTA et al., 1996).

Dessa forma, por se localizar em países de mercados mais fracos e caracterizados por posturas menos consistentes em relação às necessidades dos investidores, espera-se que as empresas de países de civil law desfrutem de menor reputação e, consequentemente, registrem menor desempenho.

A Tabela 2 ilustra a representatividade das 84 empresas da amostra por tipo de sistema jurídico vigente em cada país-sede.

Tabela 2 - Distribuição quantitativa das empresas da amostra por país-sede e sistema jurídico

\begin{tabular}{l|c|c}
\hline \multicolumn{1}{c}{ País } & Sistema Jurídico & Quantidade \\
\hline Alemanha & civillLaw & 5 \\
\hline Austrália & common law & 2 \\
\hline Bélgica & civil law & 1 \\
\hline Bermudas & common law & 1 \\
\hline Cingapura & mixed law & 3 \\
\hline Coreia do Sul & mixed law & 1 \\
\hline Dinamarca & civil law & 28 \\
\hline Estados Unidos da América & common law & 1 \\
\hline Finlândia & civil law & 6 \\
\hline França & civil law & 2 \\
\hline Holanda & civil law & 1 \\
\hline Hong Kong & mixed law & 4 \\
\hline Índia & mixed law & 1 \\
\hline Indonésia & mixed law & 1 \\
\hline Itália & civil law & 14 \\
\hline Japão & mixed law & 1 \\
\hline Jordânia & mixed law & 5 \\
\hline Reino Unido & mixed law & 2 \\
\hline Suécia & civil law & 3 \\
\hline Suíça & civil law & 1 \\
\hline Taiwan & mixed law & \\
\hline Total civil law & $\mathbf{2 2}$ & \\
Total common law & $\mathbf{3 1}$ & \\
Total mixed law & 31 & \\
\hline & TOTAL & \\
\hline Fonte: ERabora & \\
\hline
\end{tabular}

Fonte: Elaborada pelos autores, a partir de Juriglobe (2013).

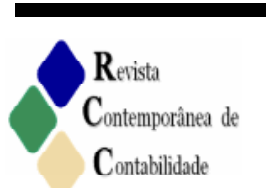


Das 84 empresas da amostra, 22 (26\%) se localizam em países com sistema civil law, 31 (37\%) são sediadas em países common law e as 31 restantes (37\%) atuam em países de mixed law. Percebe-se, também, que os EUA concentram 28 empresas da amostra (1/3), enquanto o Japão reúne 14 empresas.

A representação gráfica das relações conceituais e operacionais da pesquisa é sintetizada em libby boxes, na Figura 2, que representa o modelo de validade preditiva para ilustrar o processo da investigação.

\section{Figura 2 - Modelo de validade preditiva da pesquisa}

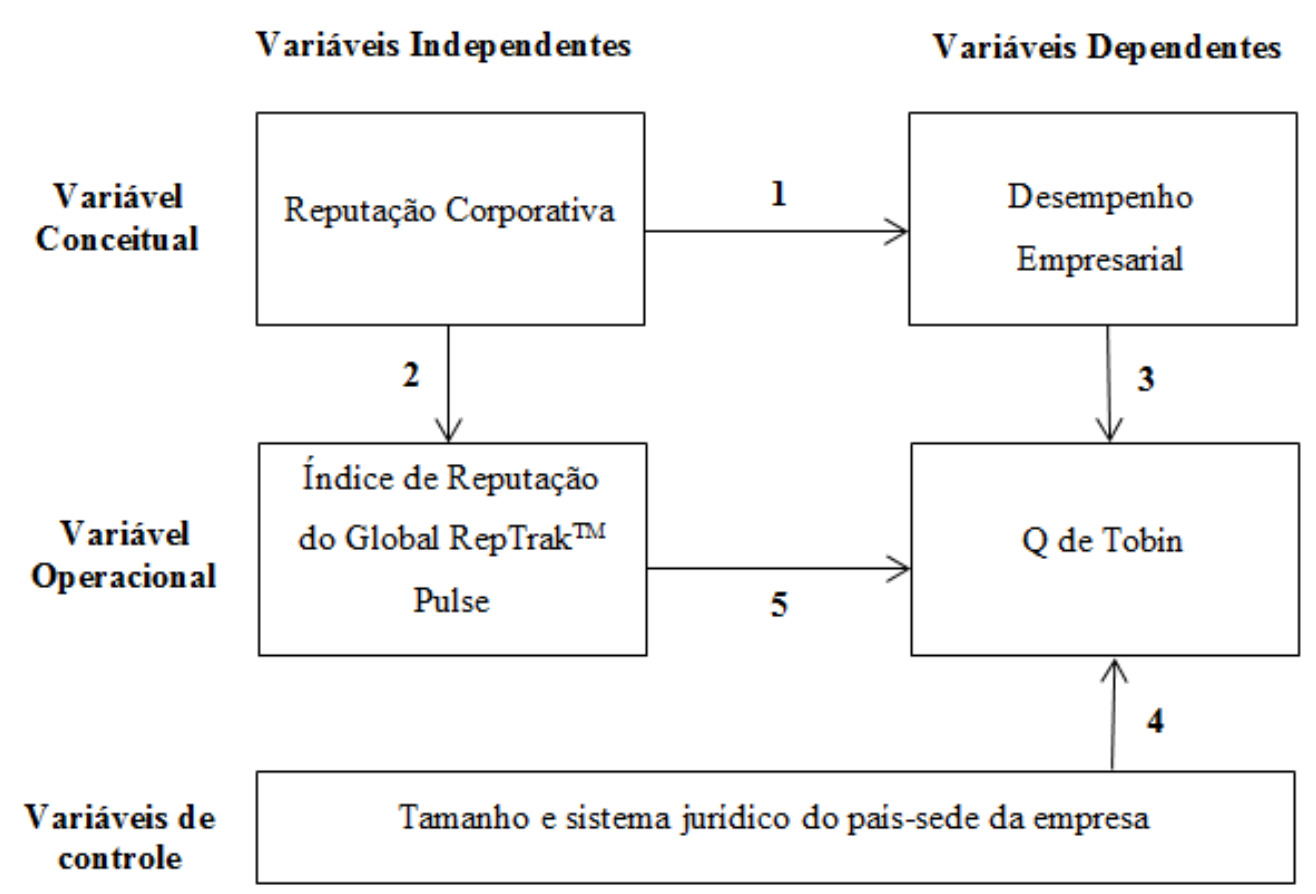

Fonte: Elaborada pelos autores.

Legenda: 1: Validade externa; 2 e 3: Validade do constructo; 4: Validade estatística; 5: Validade interna

A ligação 1 representa a relação teórica de dependência entre os conceitos de reputação corporativa e desempenho empresarial. As relações 2 e 3 configuram a operacionalização das variáveis dependente (link 3) e independente (link 2). Além disso, o link 5 corresponde à relação entre a variável operacional dependente e as variáveis operacionais independentes, e o link 4 representa a relação entre as variáveis de controle que também poderiam afetar o desempenho empresarial.

\section{Resultados e Discussão}

Esta seção destina-se à apresentação e análise dos resultados do estudo. Inicialmente, realizou-se uma análise descritiva dos dados, a fim de se compreender a sua distribuição. A Tabela 3 traz a estatística descritiva.

O indicador de reputação corporativa foi a variável que assinalou a menor variação, correspondente a um coeficiente de variação de 5,9\%; o logaritmo do $Q$ de Tobin registrou o 
maior coeficiente de variação, com $82,3 \%$, sugerindo que o desempenho das 84 empresas comportou-se de forma bastante heterogênea. A variável "tamanho" obteve uma variação média, cujo coeficiente de variação de $21,24 \%$ indica que nem todas possuem o mesmo porte. As variáveis D1 e D2 possuem igual quantidade de empresas (31 em cada). Dessa forma, era de se esperar as características descritivas similares. A média do $Q$ de Tobin, verificando o antilogaritmo, é de 0,5933 .

Tabela 3 - Estatística descritiva

\begin{tabular}{l|c|c|c}
\hline \multicolumn{1}{c|}{ Variável } & Média & Desvio-padrão & Coeficiente de variação \\
\hline REP & 72,075 & 4,2588 & 0,059088 \\
\hline LOGQTOBIN & $-0,52208$ & 0,42945 & 0,82258 \\
\hline TAMANHO & 4,8701 & 1,0302 & 0,21154 \\
\hline D1 & 0,36905 & 0,48545 & 1,3154 \\
\hline D2 & 0,36905 & 0,48545 & 1,3154 \\
\hline D3 & 0,26190 & 0,26190 & 1,6888 \\
\hline
\end{tabular}

Fonte: Dados da pesquisa.

Uma vez concluída a análise descritiva, passou-se à análise de correlação entre as variáveis consideradas no estudo. Na Tabela 4 são dispostos os coeficientes referentes à correlação entre as variáveis dependente e independente.

Tabela 4 - Correlação entre as variáveis

\begin{tabular}{r|r|r|r|r|r|l}
\hline TAMANHO & REP & \multicolumn{1}{c|}{ D1 } & \multicolumn{1}{c|}{ D2 } & \multicolumn{1}{c|}{ D3 } & LOGQTOBIN & \\
\hline 1,0000 & 0,1357 & $-0,2652$ & 0,3513 & $-0,0944$ & $-0,1840$ & TAMANHO \\
\hline & 1,0000 & 0,0390 & $-0,1275$ & 0,0971 & $-0,2343$ & REP \\
\hline & & 1,0000 & $-0,5849$ & $-0,4556$ & 0,0234 & D1 \\
\hline & & & 1,0000 & $-0,4556$ & $-0,0876$ & D2 \\
\hline & & & & 1,0000 & 0,0705 & D3 \\
\hline & & & & & 1,0000 & LOGQTOBIN \\
\hline
\end{tabular}

Fonte: Dados da pesquisa.

As dummies, geralmente, apresentam uma correlação elevada, podendo criar uma correlação perfeita, causando problemas na regressão. Uma das formas de eliminar esse problema é usar a fórmula $(\mathrm{n}-1)$ dummies no modelo, ou fazer a permanência de apenas uma das dummies (a melhor correlacionada com y). A variável REP possui a melhor correlação com a variável do $Q$ de Tobin, forte candidata a possuir uma relação significativa.

Antes de proceder à análise de regressão, vale comentar acerca dos pressupostos da regressão, que são a homocedasticidade, a independência dos resíduos e a multicolinearidade. Foi feita uma regressão robusta, o que evita a ocorrência de homocedasticidade. Não há autocorrelação serial dos resíduos, haja vista que essa análise é cross-section. E, também, não há multicolinearidade, conforme apresentado na tabela de correlação (Tabela 4). Importa enfatizar que foi utilizada regressão robusta, razão pela qual não se mostra apropriada a análise de multicolinearidade por meio do Variance Inflation Factor (VIF), pois a variância vai ser inflacionada, modificando o resultado real do indicador.

Assim, após a análise de correlação, foi realizada regressão robusta por Mínimos Quadrados Ordinários, primeiramente observando-se a influência da reputação corporativa no desempenho empresarial, conforme sugere a VBR. A variável D3 foi omitida, devido à colinearidade exata.

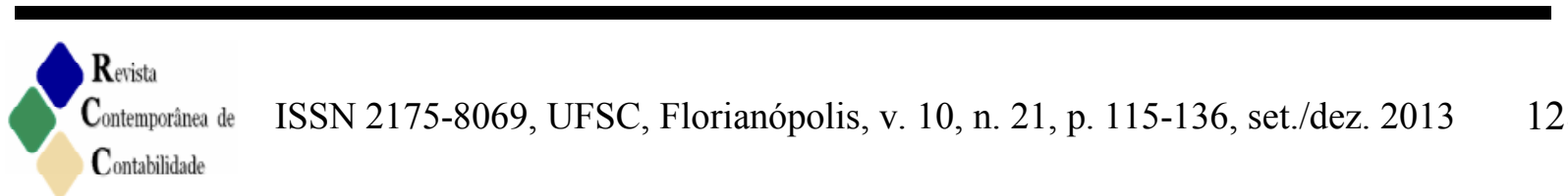


Inicialmente, é possível observar que o modelo estatístico não apresentou significância quanto ao teste $\mathrm{F}$, sugerindo que nenhuma das variáveis independentes influencia na variável dependente. Contudo, ao analisar as variáveis individualmente, a Tabela 5 indica que a maior reputação sugere maior $Q$ de Tobin, uma vez que o antilogaritmo da variável reputação (LOGREP) apresentou significância ao nível de 5\%, bem como apresentou o coeficiente positivo. O $Q$ de Tobin aumenta, em média, $20 \%$ a cada aumento em unidade da reputação corporativa. As variáveis tamanho, D1 e D2 não apresentaram significância estatística, mas pode-se observar que se houvesse significância, o maior tamanho implicaria maior reputação.

Tabela 5 - Mínimos Quadrados Ordinários com a variável dependente $Q$ de Tobin

\begin{tabular}{l|c|c|c|c}
\hline \multicolumn{1}{c|}{ Variável } & Coeficiente & Erro-padrão & t & Valor-p \\
\hline Constante & 6,61769 & 3,34955 & 1,976 & $0,0517(*)$ \\
\hline LOGREP & $0,200000^{* * * *}$ & 0,789469 & $-2,017$ & $0,0471(* *)$ \\
\hline TAMANHO & $0,950000^{* * * *}$ & 0,0489450 & $-1,148$ & 0,2543 \\
\hline $\mathrm{D} 1$ & $-0,0599167$ & 0,117885 & $-0,5083$ & 0,6127 \\
\hline $\mathrm{D} 2$ & $-0,0944346$ & 0,123113 & $-0,7671$ & 0,4453 \\
\hline $\mathrm{R}^{2}$ ajustado & 0,037498 & & & \\
\hline Valor-p (F) & 0,135478 & & & \\
\hline
\end{tabular}

$(* * *)$ significativo a $1 \%,(* *)$ significativo a $5 \%,(*)$ significativo a $10 \%$.

**** As variáveis são o antilogaritmo das variáveis transformadas, sendo a variável analisada quando comparada ao valor de y. Adotou-se transformação de Box-Cox (FAVERO et al., 2009)

Fonte: Dados da pesquisa.

Como preconizado pela VBR e considerado na hipótese deste estudo, as evidências sugerem que a reputação corporativa está positivamente associada ao desempenho empresarial. Em se tratando de análise de regressão, verificou-se que a reputação influencia a formação do desempenho das companhias analisadas.

Esse resultado corrobora os achados das pesquisas de Fombrun e Shanley (1990), Roberts e Dowling (2002), Schultz, Nielsen e Boege (2002), Horiuchi (2010) e Thomaz e Brito (2010). Contudo, cabe ressaltar que cada estudo apresenta suas particularidades, sejam de amostra, sejam de método de avaliação da reputação corporativa ou do desempenho.

A pesquisa de Fombrun e Shanley (1990), realizada com empresas britânicas, a de Roberts e Dowling (2002), com base no ranking “As Empresas Mais Admiradas da América", da revista Fortune, e a de Schultz, Nielsen e Boege (2002), com empresas da Dinamarca, constataram a correlação positiva entre reputação corporativa e desempenho empresarial, porém cada um em seu contexto, os quais foram diferentes da presente pesquisa, cuja abrangência se deu em âmbito mundial, limitando-se aos países de atuação do Reputation Institute.

Horiuchi (2010) utilizou como variável de desempenho o valor de mercado das ações, constatando uma valorização na avaliação pelo mercado de ações das empresas com a característica que as classifica como empresas com boa reputação, corroborando, assim, os resultados da presente pesquisa. Thomaz e Brito (2010) também obtiveram resultados que coadunam com os do presente estudo, haja vista que constataram a correlação positiva, porém moderada entre os dois fatores - desempenho e reputação.

Os estudos de Caixeta (2008) e Caixeta et al. (2011) não constataram qualquer relação entre a reputação e o desempenho. Contudo, os referidos estudos limitaram-se às dimensões do RepTrack ${ }^{\mathrm{TM}}$ relativas à governança, a desempenho e a produtos e serviços, enquanto a presente pesquisa considera o escore geral da reputação, cuja abrangência se dá nas seguintes 
dimensões: desempenho, produtos e serviços, inovação, ambiente de trabalho, governança, cidadania e liderança. Logo, a discrepância entre os achados das citadas pesquisas e os do presente estudo pode ter sido devido à diferença de abrangência de fatores relativos à reputação corporativa, considerados pelo Reputation Institute.

Além desses estudos, o de Brito (2005) também não detectou qualquer relação entre a reputação e o desempenho. A autora constatou que o desempenho empresarial era explicado, em sua maioria, pela percepção da imagem e da identidade corporativa. Vale ressaltar que o estudo de Brito (2005) não considerou a reputação corporativa como fator sinônimo de imagem e identidade, como fazem outros estudos, segundo Gotsi e Wilson (2001).

Nesse sentido, pode-se inferir que a reputação corporativa, considerada nesta pesquisa como um ativo intangível, é capaz de contribuir para a conquista de um melhor desempenho empresarial, na medida em que constitui um recurso valioso, raro, de difícil imitação (TEIXEIRA; POPADIUK, 2003) e particular de cada empresa, capaz de diferenciá-la no mercado e contribuir na gestão organizacional (OENING, 2010). No caso de boa reputação, essa diferenciação é positiva (BARNEY, 1991; CARVALHO; KAYO; MARTÍN, 2010). Sendo assim, a reputação corporativa se firma como uma estratégia empresarial que visa alcançar desempenho melhor do que aqueles obtidos por suas concorrentes, e a implementação dessa estratégia propicia benefícios para a companhia (CASTRO, 2009).

Complementarmente, o presente estudo considerou o modelo da dinâmica da reputação e desempenho financeiro de Roberts e Dowling (2002), mostrado na Figura 1, a qual ilustra que além de influenciar o desempenho empresarial, a reputação corporativa pode também ser influenciada pelo desempenho. Vale ressaltar que nesse modelo, apresentado na Tabela 6, no qual a variável dependente é a reputação corporativa, a variável D3 foi omitida, devido a sua colinearidade exata.

Tabela 6 - Mínimos Quadrados Ordinários robustos com a variável dependente Reputação Corporativa

\begin{tabular}{l|c|c|c|c}
\hline \multicolumn{1}{c|}{ Variável } & Coeficiente & Erro-padrão & t & Valor-p \\
\hline Constante & 68,5376 & 2,26131 & 30,31 & $2,93 \mathrm{e}-45(* * *)$ \\
\hline LOGQTOBIN & $0,1090 * * *$ & 0,948924 & $-2,336$ & $0,0221(* *)$ \\
\hline TAMANHO & $1,9662 * * * *$ & 0,459121 & 1,473 & 0,1448 \\
\hline D1 & $-0,426997$ & 1,20359 & $-0,3548$ & 0,7237 \\
\hline D2 & $-2,04433$ & 1,16340 & $-1,757$ & $0,0828(*)$ \\
\hline $\mathrm{R}^{2}$ ajustado & 0,056923 & & & \\
\hline Valor-p (F) & 0.070802 & & & \\
\hline (**) significativo a 1\%, $(* *)$ & significativo a 5\%, $(*)$ significativo a $10 \%$. \\
$* * * *$ As variáveis são o antilogaritmo das variáveis transformadas, sendo a variável analisada quando comparada
\end{tabular}
ao valor de y. Adotou-se a transformação de Box-Cox (FAVERO et al., 2009).

Fonte: Dados da pesquisa.

A Tabela 6 indica a significância estatística no nível de 10\% do modelo. Além disso, percebe-se que a variável $Q$ de Tobin obteve sinal positivo, quando observado o seu antilogaritmo, significando que quanto maior for o $Q$ de Tobin, maior é a reputação corporativa da companhia. Em média, a reputação aumenta 10,9\% a cada aumento em unidade do $Q$ de Tobin. As variáveis tamanho e $\mathrm{D} 1$ não foram significativas, mas quanto maior o tamanho da empresa, maior é sua reputação. Apenas a dummy D2 foi significativa e demonstra uma relação negativa com a variável reputação, mostrando que ser de país de sistema jurídico misto (mixed law) traz uma variação negativa com a reputação. Dessa forma,

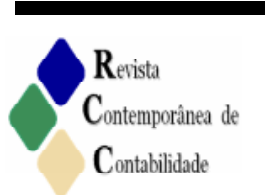

ISSN 2175-8069, UFSC, Florianópolis, v. 10, n. 21, p. 115-136, set./dez. 2013 
quando a empresa possui a propriedade de ser de um país com característica mista, ele tem relação inversa com a variável reputação. Ter sede em um país com common law não possui significância. E a variável D3 foi retirada por colinearidade exata.

Logo, as evidências apontam para a aprovação do modelo da dinâmica da reputação e desempenho financeiro de Roberts e Dowling (2002), visto que o desempenho é também capaz de influenciar a reputação corporativa.

\section{Considerações Finais}

O presente estudo teve por objetivo investigar a relação entre a reputação corporativa e o desempenho das empresas com melhor reputação, assim classificadas segundo o Reputation Institute. Para tanto, realizou-se um estudo descritivo, com abordagem quantitativa dos dados, utilizando-se uma amostra de 84 empresas dentre as 100 melhores do Global RepTrak ${ }^{\mathrm{TM}}$ Pulse, do Reputation Institute.

Observou-se que a melhor reputação corporativa - neste estudo representada pela pontuação no Global RepTrak ${ }^{\mathrm{TM}}$ Pulse - implica melhor desempenho, podendo-se inferir que essa característica pode impulsionar o melhor desempenho empresarial, em conformidade com o que preconiza a VBR e corroborando resultados de outras pesquisas sob enfoque similar (FOMBRUN; SHANLEY, 1990; ROBERTS; DOWLING, 2002; SCHULTZ; NIELSEN; BOEGE, 2002; HORIUCHI, 2010; THOMAZ; BRITO, 2010; ROSSONI; MACHADO-DA-SILVA, 2013).

De forma mais específica, verificou-se que o sistema jurídico do país-sede da empresa pode influenciar a reputação corporativa. Sobre esse aspecto, observou-se que empresas provenientes de países com sistema jurídico misto têm relação inversa com a reputação, ou seja, possuem menor reputação que a das empresas sediadas em países de sistema jurídico common law ou civil law.

Dessa forma, a melhor reputação corporativa, sendo esta considerada ativo intangível, recurso valioso, raro, de difícil imitação e particular de cada empresa, é preponderante na explicação do melhor desempenho das empresas. Logo, confirma-se a hipótese inicialmente mencionada, de que a boa reputação corporativa se relaciona positivamente com o desempenho empresarial.

Conclui-se, portanto, que a reputação corporativa assume um papel estratégico nas empresas, uma vez que, segundo estudos empíricos expostos na presente pesquisa, bem como os achados observados, empresas cuja reputação tem índices mais altos detêm melhores desempenhos.

Logo, a implementação de práticas voltadas para a conquista e melhoria constante da reputação corporativa deve ser uma estratégia permanente das empresas visando ao melhor desempenho, tendo em vista que a reputação representa um bem capaz de proporcionar benefício futuro às empresas, atuando como ativo intangível. É importante ressaltar ainda que a conquista da reputação se dá, principalmente, pela conservação da imagem corporativa no tocante ao âmbito social, ambiental, aos produtos e serviços, à governança e inovação demonstrada pela empresa aos seus stakeholders.

O presente estudo se agrega aos demais que abordam o tema reputação corporativa, na perspectiva da investigação do melhor desempenho como um dos benefícios conquistados pela obtenção de uma boa reputação corporativa, sob a fundamentação teórica da VBR. 
Tais constatações são relevantes, pois fornecem indícios empíricos da relação entre a reputação, representada por um indicador de abrangência mundial - Global RepTrak ${ }^{\mathrm{TM}}$ Pulse do Reputation Institute - e o desempenho empresarial, bem como o sistema jurídico adotado pelo país-sede da organização como fator determinante para a formação da reputação corporativa.

A importância desses achados reside, principalmente, no âmbito estratégico das empresas e pode contribuir para decisões gerenciais, pois possibilita uma reflexão quanto aos fatores condicionantes do melhor desempenho empresarial, o que representa o objetivo primordial das organizações como fator de continuidade das suas operações.

Embora a metodologia e a análise tenham proporcionado o alcance dos objetivos, vale ressaltar algumas limitações do presente estudo, dentre as quais se destacam o curto período de um ano para análise e a restrição das proxies utilizadas, principalmente para a reputação corporativa. Dessa forma, propõe-se o desenvolvimento de estudos futuros que contribuam para o entendimento dessa relação entre reputação corporativa e desempenho empresarial, procedendo-se também a uma análise temporal. Além disso, sugere-se a realização da análise com método de delimitação da amostra diferenciado.

\section{Referências}

ALMEIDA, A. L. A influência da identidade projetada na reputação organizacional. 360 f. 2005. Tese (Doutorado em Administração) - Faculdade de Ciências Econômicas, Universidade Federal de Minas Gerais, Belo Horizonte, 2005.

ALMEIDA-SANTOS, P. S. et al. Nível de disclosure verde e a reputação corporativa ambiental das companhias brasileiras de capital aberto. Revista Contemporânea de Contabilidade. V.9, n.18, p. 63-82, jul./dez. 2012.

BARNETT, M. L.; JERMIER J. M.; LAFFERTY B. A. Corporate reputation: the definitional landscape. Corporate Reputation Review. V. 9, n. 1, p. 26-38, 2006.

BARNEY, J. B. Firm resources and sustained competitive advantage. Journal of Management. Greenwich, v. 17, n. 1, p. 99-120, 1991.

BRITO, E. Reputação e desempenho: uma análise empírica no setor bancário. Revista Economia e Gestão. V. 5, n. 11, p. 117-142, 2005.

BUSHMAN, R. M.; PIOTROSKI, J. D. Financial reporting incentives for conservative accounting: the influence of legal and political institutions. Journal of Accounting and Economics. V. 42, n. 1-2, p. 107-148, 2006.

CAIXETA, C. G. F. Competitividade brasileira: um estudo da reputação de empresas nacionais por meio das dimensões governança, desempenho e produtos e serviços. $128 \mathrm{f}$. 2008. Dissertação (Mestrado em Administração) - Pontifícia Universidade Católica de Minas Gerais, Belo Horizonte, 2008.

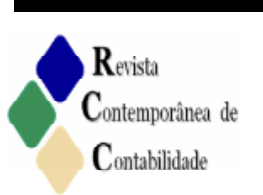


CAIXETA, C. G. F. et al. Reputação corporativa e desempenho econômico-financeiro: um estudo em cinco grandes grupos empresariais brasileiros. Revista Eletrônica de Gestão Organizacional. V. 1, n. 9, p. 86-109, 2011.

CARMO, C. H.; RIBEIRO, A. M.; CARVALHO, L. N. G. Convergência de fato ou de direito? A influência do sistema jurídico na aceitação das normas internacionais para pequenas e médias empresas. Revista Contabilidade \& Finanças - USP. V. 22, n. 57, p. 242-262, 2011.

CARVALHO, F. M.; KAYO, E. K.; MARTÍN, D. M. L. Tangibilidade e intangibilidade na determinação do desempenho persistente de firmas brasileiras. Revista de Administração Contemporânea - RAC. v. 14, n. 5, p. 871-889, 2010.

CASTRO, D. J. Em busca da "reputação corporativa": perspectivas conceituais e metodológicas. In: SEMINÁRIOS EM ADMINISTRAÇÃO - SEMEAD, 7., 2009, São Paulo. Anais. São Paulo: FEA-USP, 2009.

CRISÓSTOMO, V. L.; FREIRE, F. S.; VASCONCELLOS, F. C. Corporate social responsibility, firm value and financial performance in Brazil. Social Responsibility Journal. Apr. 2010. Disponível em: <http://ssrn.com/abstract=1587023>. Acesso em: 28 jan. 2013.

CUNHA, J. V. A.; COELHO, A. C. Regressão linear múltipla. In: CORRAR, L. J.; PAULO, E.; DIAS-FILHO, J. M. (Coord.). Análise multivariada: para os cursos de administração, ciências contábeis e economia. São Paulo: Atlas, 2007, p. 131-231.

DRAGOMIR, V. D. Environmentally sensitive disclosures and financial performance in a European setting. Journal of Accounting \& Organizational Change. V. 6, n. 3, p. 359-388, 2010 .

FAMÁ, R.; BARROS, L. A. B. Q de Tobin e seu uso em finanças: aspectos metodológicos e conceituais. Caderno de Pesquisas em Administração. V. 7, n. 4, p. 27-43, 2000.

FÁVERO, L. P. L. et al. Análise de dados: modelagem multivariada para tomada de decisões. São Paulo: Campus, 2009.

FOMBRUN, C. J.; SHANLEY, M. What's in a name? Reputation building and corporate strategy. Academy of Management Journal, Mississippi. v. 33, n. 2, p. 233-58, 1990.

FOMBRUN, C. J.; SHANLEY, M.; GARDBERG, N. A.; SEVER, J. M. The reputation quotient $^{\mathrm{SM}}$ : a multi-stakeholder measure of corporate reputation. The Journal of Brand Management. V. 7, n. 4, p. 241-255, 2000.

FREITAS, M. E. Cultura organizacional: evolução e crítica. São Paulo: Pioneira Thomson Learning, 2007. 
GIRARD, A. C. A influência da comunicação na reputação corporativa do Banco Itaú. 153 f. 2009. Dissertação (Mestrado em Administração) - Pontifícia Universidade Católica de Minas Gerais, 2009.

GOTSI, M.; WILSON, A. M. Corporate reputation: seeking a definition. Corporate Communications. v. 6, n. 1, p. 24-30, 2001.

HORIUCHI, W. S. Reputação corporativa: impacto no valor de mercado das companhias abertas brasileiras. 61 f. 2010. Dissertação (Mestrado em Administração) - Insper Instituto de Ensino e Pesquisa, São Paulo, 2010.

JURIGLOBE. World Lega Systems - Research Group. Disponível em: $<$ http://www.juriglobe.ca/eng/index.php>. Acesso em: 25 jan. 2013.

LA PORTA, R. et al. Law and finance. Working Paper 5661, Cambridge, Mass: National Bureau of Economics, 1996.

LAKATOS, E. M.; MARCONI, M. Fundamentos da metodologia científica. São Paulo: Atlas, 1985.

LANDON, S.; SMITH, C. E. The use of quality and reputation indicators by consumers: the case of bordeaux wine. Journal of Consumer Policy. V. 20, p. 289-323, 1997.

MACHADO, J. H.; FAMÁ, R. Ativos intangíveis e governança corporativa no mercado de capitais brasileiro. Revista Contemporânea de Contabilidade. V.8, n. 16, p. 89-110, jul./dez. 2011.

MACHADO FILHO, C. P. Responsabilidade social e governança: o debate e as implicações: responsabilidade social, instituições, governança e reputação. São Paulo:

Pioneira Thomson Learning, 2006.

MAHON, J. F. Corporate reputation: research agenda using strategy and stakeholder literature. Business Society, v. 41, n. 415, p. 414-445, 2002. Disponível em: $<$ http://bas.sagepub.com/content/41/4/415>. Acesso em: 14 dez. 2012.

MICHELON, G. Sustainability disclosure and reputation: a comparative study. Università DegliStudi di Padova. Marco Fanno: Working paper. Set. 2007.

MURCIA, F. D. Fatores determinantes do nível de disclosure voluntário de companhias abertas no Brasil. 2009. 182 f. Tese (Doutorado em Ciências Contábeis) - Programa de PósGraduação em Ciências Contábeis, Universidade de São Paulo.

MURCIA, F. D.; SANTOS, A. Fatores determinantes do nível de disclosure voluntário das companhias abertas no Brasil. Revista de Educação e Pesquisa em Contabilidade. V. 3, p. 72-95, 2009. 
NAICS - North American Industry Classification System. Disponível em:

$<$ http://www.naics.com>. Acesso em: 28 jan. 2013.

OENING, K. S. Pluralismo teórico na gestão estratégica: a compreensão da vantagem competitiva a partir da harmonização de perspectivas antagônicas. Revista de Negócios. V. 15, n. 1, p. 45-56, 2010.

OLIVEIRA, S. L. Tratado de metodologia científica. São Paulo: Pioneira. Thomson Learning, 2001.

PRADO, J. M. L. et al. Factors influencing the disclosure of greenhouse gas emissions in companies world-wide. Management Decision. v. 47, p. 1.133-1.157, 2009.

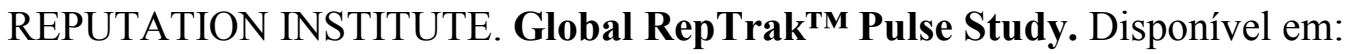
$<$ http://www.reputationinstitute.com/thought-leadership/global-reptrak>. Acesso em: 28 jan. 2013.

ROBERTS, P. W.; DOWLING, G. R. Corporate reputation and sustained superior financial performance. Strategic Management Journal. V. 23, n. 12, p. 1.077-1.093, Dez. 2002.

ROSSONI, L.; MACHADO-DA-SILVA, C. Legitimidade, governança corporativa e desempenho: análise das empresas da BM\&FBovespa. Revista de Administração de Empresas - era. V. 53, n. 3, p. 272-289, maio/jun. 2013.

SCHULTZ, M.; NIELSEN, K. U.; BOEGE, S. Nominations for the most visible companies for the danish RQ. Corporate Reputation Review. V. 4, n. 1, p. 327-336, 2002.

SCHULTZ, M.; MOURITSEN. J.; GABRIELSEN, G. Sticky reputation: analyzing a ranking system. Corporate Reputation Review. V. 4, n. 1, p. 24-41, 2001.

SILVA, M. F. O. A vantagem competitiva das nações e a vantagem competitiva das empresas: a localização e importante? 204 f. 2009. Tese (Doutorado em Administração) Pontifícia Universidade Católica do Rio de Janeiro, Rio de Janeiro, 2009.

SILVEIRA, A.; BARROS, L. Determinantes da qualidade da governança corporativa das companhias abertas brasileiras. Revista Eletrônica de Administração. V. 14, p. 1-15, 2008.

SILVEIRA, A. et al. Efeito dos acionistas controladores no valor das companhias abertas brasileiras. Revista de Administração. V. 39, p. 362-372, 2004.

TEIXEIRA, M. L. M.; POPADIUK, S. Confiança e desenvolvimento de capital intelectual: o que os empregados esperam de seus líderes? Revista de Administração Contemporânea RAC. V. 7, n. 2, abr./jun. 2003. 
THOMAZ, J. C.; BRITO, E. P. Z. Reputação corporativa: construtos formativos e implicações para a gestão. Revista de Administração Contemporânea - RAC. V. 14, n. 2, p. 229-250, mar./abr. 2010.

WERNERFELT, B. A resource-based view of the firm. Strategic Management Journal. V. 5, n. 2, p. 171-180, 1984. 